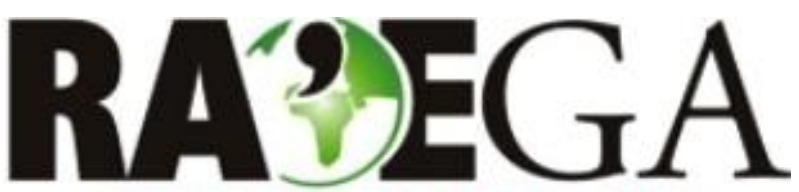

O ESPAÇO GEOGRÁFICO EM ANÁLISE

\title{
AS CARACTERÍSTICAS NA MORFOLOGIA E DA CARGA DE FUNDO NAS CONFLUÊNCIAS DO RIO IVINHEMA-MS COM O RIO PARANÁ
}

\section{CHARACTERISTICS IN MORPHOLOGY AND BOTTOM LOAD AT THE CONFLUENCES OF IVINHEIMA RIVER WITH PARANÁ RIVER}

\author{
Vanderlei Grzegorczyk ${ }^{1}$, Manoel Luiz Dos Santos ${ }^{2}$, Dayane Pagotto ${ }^{3}$
}

\section{RESUMO}

O estudo da dinâmica sedimentar e geomorfológica de confluências fluviais é muito restrito no Brasil. Esta pesquisa aborda aspectos dos processos geomorfológicos e sedimentares nas áreas de confluências do rio Ivinhema-MS, com o rio Paraná no ano de 2013. A bacia hidrográfica desta área está inserida na bacia sedimentar do Paraná. O rio Ivinhema-MS no curso inferior corre sobre depósitos aluviais, quaternários, planícies e terraços do sistema aluvial do rio Paraná e apresenta três confluências que deságuam no rio Paraná. O rio Paraná é um rio multicanal e cada canal possui características próprias de hidrodinâmica, de transporte de sedimentos, velocidade de fluxos e de processos geomorfológicos. Foram escolhidas 12 seções transversais onde se coletaram amostras de carga de fundo, dados de velocidade, direção do fluxo e vazão do canal. Utilizou-se o sensoriamento remoto, aerofotos e cartas topográficas no reconhecimento da área. Mapas batimétricos foram gerados com os dados obtidos pela ecossonda Furuno GP-1650-F, acoplada a um GPS. O rio Paraná movimenta grandes quantidades de carga de fundo durante o ano, promovendo grandes alterações geomorfológicas. A areia grossa e os cascalhos são encontrados nas áreas de maior energia de fluxo e o material pelítico próximo às margens, em ambos os rios. No rio Ivinhema-MS, areia grossa e cascalho têm origem no processo erosivo das cascalheiras. A carga de fundo predominante na área da pesquisa é de areia fina a média.

Palavras-chave: Processos Sedimentares, Geomorfologia de Confluências, Carga Hidrotransportada

\section{ABSTRACT}

Studies on the sedimentary and geomorphological dynamics of fluvial confluences is very restricted in Brazil. This work addresses aspects of geomorphological and sedimentary processes at the confluences of the Ivinhema River (State of Mato Grosso do Sul) with the Paraná River in 2013. The watershed of this area is inserted in the Paraná sedimentary basin. The lower stretch of the Ivinhema River flows on alluvial and quaternary deposits, plains and terraces of the Paraná River alluvial system and has three confluences that flow into the Paraná River. The Paraná River is a multichannel river and each channel has its own characteristics of hydrodynamics, sediment transport, velocity of flows and geomorphological processes. Twelve cross-sections were selected, where we collected, bottom load samples, data of flow velocity, flow direction and channel flow. For recognition of the area, we used remote sensing, aerial photos and topographic charts. Bathymetric maps were generated with data obtained by a Furuno GP-1650- F echo sounder, coupled to a GPS. The Paraná river displaces large amounts of bottom load during the year, which promotes great geomorphological changes. Coarse sand and gravel are found in areas of higher flow energy and the pelitic is deposited near the banks of both rivers. In the Ivinhema River, coarse sand and gravel originate from the erosive process of the oligomitic gravel beds. The predominant bottom load in the study area is fine to medium sand.

Key-words: Sedimentary Processes, Confluence Geomorphology, Hydrotransported Load.

Recebido em: 26/07/2017

Aceito em: 20/02/2019

\footnotetext{
${ }^{1}$ Universidade Estadual de Maringá, Maringá/PR, e-mail:vanderleigk@gmail.com

${ }^{2}$ Universidade Estadual de Maringá, Maringá/PR, e-mail: mluisdossantos@gmail.com

${ }^{3}$ Universidade Estadual de Maringá, Maringá/PR, e-mail: dayane_pagotto@hotmail.com
} 


\section{AS CARACTERÍSTICAS NA MORFOLOGIA E DA CARGA DE FUNDO NAS CONFLUÊNCIAS DO RIO IVINHEMA-MS COM O RIO PARANÁ}

\section{INTRODUÇÃO}

Os estudos sobre bacias hidrográficas, no Brasil, aumentaram nas últimas décadas, em que são destacados os trabalhos realizados na bacia Amazônica e na bacia do rio Paraná. Esta última conta com inúmeras pesquisas realizadas no curso médio e superior, por pesquisadores e alunos do Grupo de Estudos Multidisciplinares do Ambiente da Universidade Estadual de Maringá (GEMA/UEM). Diversos afluentes da bacia foram pesquisados com destaque aos rios Baía, Ivinhema e o canal Corubá na margem direita no Mato Grosso do Sul, os rios Ivaí na margem esquerda e recentemente o rio Piquiri no Estado do Paraná. Esta pesquisa aborda a relação entre o transporte de carga do rio Ivinhema no Mato Grosso do Sul com o rio Paraná no ano de 2013.

$$
\text { O estudo }
$$

geomorfológico da confluência de sistemas fluviais é pouco difundido mais notadamente quando se trata de grandes rios brasileiros. Porém, é na região da confluência que ocorre a interação da hidrodinâmica de cursos fluviais acarretando sensíveis mudanças nos processos geomorfológicos e sedimentares de ambos os canais nesta região. Somente estes aspectos já justificariam este estudo. A reação de um sistema fluvial às mudanças em suas variáveis dominantes é extremamente complexa, tanto em escala espacial como temporal. Assim sendo, a abordagem geomorfológica da região das confluências fluviais traz resultados expressivos e realísticos para os estudos ambientais. Os estudos da geomorfologia fluvial incluem o conhecimento da característica do fluxo de águas e de sedimentos, da morfologia, dos processos atuais, da evolução e do comportamento das variáveis intervenientes no sistema fluvial ao longo do tempo.

A bacia hidrográfica do rio IvinhemaMS (Figura 1) é parte da bacia do rio Paraná, localizada em território brasileiro na região Centro-Oeste, no Estado de Mato Grosso do Sul, fazendo fronteira com o Paraguai na sua porção sudoeste. Possui área de aproximadamente $44.837,15 \mathrm{~km}^{2}$ e seu curso principal percorre uma distância de $568 \mathrm{~km}$, desde sua nascente na serra das Araras, até sua foz junto a margem direita do rio Paraná. Os principais afluentes nascem na serra Camapuã e Maracaju (rios Vacarias, Brilhante e Dourados) (FORTES, 2003, p.3-5; FORTES e VOLKMER, 2003, p. 40-1; FORTES, VOLKMER, e; STEVAUX, 2004, p. 1; FORTES, STEVAUX E; VOLKMER, 2005, p.327-7; e MATO GROSSO DO SUL, 2014, p.32-3). 


\section{AS CARACTERÍSTICAS NA MORFOLOGIA E DA CARGA DE FUNDO NAS CONFLUÊNCIAS DO RIO IVINHEMA-MS COM O RIO PARANÁ}

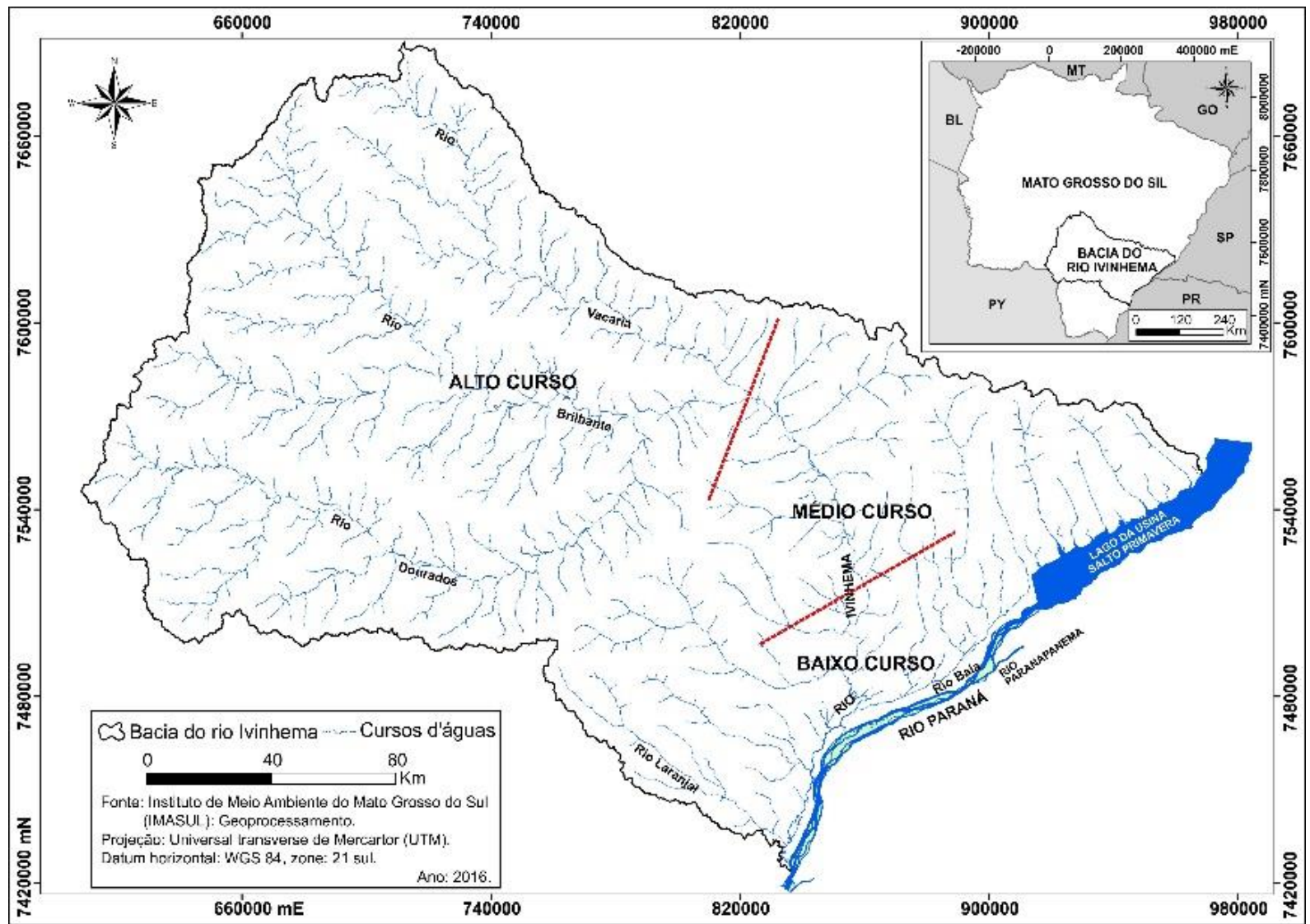

Figura 1 - Bacia hidrográfica do rio Ivinhema-MS. Fonte: Autor, com colaboração de Carlos Henrique Graça, 2015.

A bacia do rio Ivinhema-MS está inserida em sua totalidade no contexto geológico da bacia sedimentar do Paraná. Apresenta as unidades litoestratigráficas desenvolvidas no Mesozoico, (Figura 2). No Grupo São Bento encotram-se manchas de afloramentos da Formação Botucatu (Jr) e de rochas vulcânicas, predominantemente básicas da Formação Serra Geral (Jr-Kr); o Grupo Bauru ocupa a região Leste da bacia e é formado por arenitos da Formação Caiuá (Kr). Na parte inferior da bacia ocorrem os sedimentos quaternários do rio Paraná, formando planícies e terraços (SOUZA FILHO, 1993, p.7; SOUZA FILHO, e STEVAUX, 1997 P.4 STEVAUX, 1993 p. 10-1; FORTES, 2003, p.95; e MATO GROSSO DO SUL, 2014, p.52).

O rio Ivinhema-MS, no seu curso inferior, é capturado pela planície aluvial do rio Paraná seguindo a direção geral da mesma (SW-NE); ocupa e retrabalha os aluviões do rio
Paraná, construídos sobre as litogias areníticas da Formação Caiuá (Kr) que construíram o seu sistema aluvial Quaternário; apresenta em sua base conglomerados ferruginosos seguidos de uma sequência de areias e pelitos (SANTOS 1997, p.38, 2005; STEVAUX, 1993 p.14-5; SOUZA FILHO, 1993, p.10; SOUZA FILHO e STEVAUX, 1997, P.4; FORTES, 2003, p.95) (Figura 3).

O rio Ivinhema-MS, na área deste estudo, corre sobre duas unidades geomorfológicas arenopelíticas, aqui denominadas de planície Paraná e planície Paraná-Ivinhema (Figura 3), construídas pelo rio Paraná ao longo do Pleistoceno, porém a segunda sofre o retrabalhamento do rio Ivinhema-MS e do próprio rio Paraná. Esta área está sobre o regime de cheias de ambos os rios. Nestas unidades, as geoformas proximais comuns são os diques marginais e as áreas pantanosas da bacia de alagamento. Afastado 


\section{AS CARACTERÍSTICAS NA MORFOLOGIA E DA CARGA DE FUNDO NAS CONFLUÊNCIAS DO RIO IVINHEMA-MS COM O RIO PARANÁ}

dos canais, há lagoas, a maioria é alongada e alinhada segundo a direção da planície, representando a colmatação de paleocanais. As geoformas de paelocanais e de paleodiques são distribuídas ao longo de toda esta unidade.

O rio Ivinhema-MS percorre grande parte dos terraços e planícies formadas pelo rio Paraná no passado, interagindo com diversos afluentes de menor porte, lagoas e o próprio rio Paraná, nas áreas da planície do rio Paraná entre as cidades paranaenses de Icaraíma e Querência do Norte. Neste trecho, há três confluências do rio Ivinhema-MS, com canais secundários do rio Paraná, identificadas neste trabalho como confluência Ivinhema 01 , mais a jusante ao sul no município de Naviraí-MS, próximo a Icaraíma no Estado do Paraná. Confluência Ivinhema 02, localizada a montante da confluência Ivinhema 01 cerca de $1 \mathrm{~km}$ e a confluência Ivinhema 3 , localizada mais ao norte, dentro do parque estadual do Ivinhema, próxima ao município de Querência do Norte à direita do rio Paraná, nessa área de estudo.

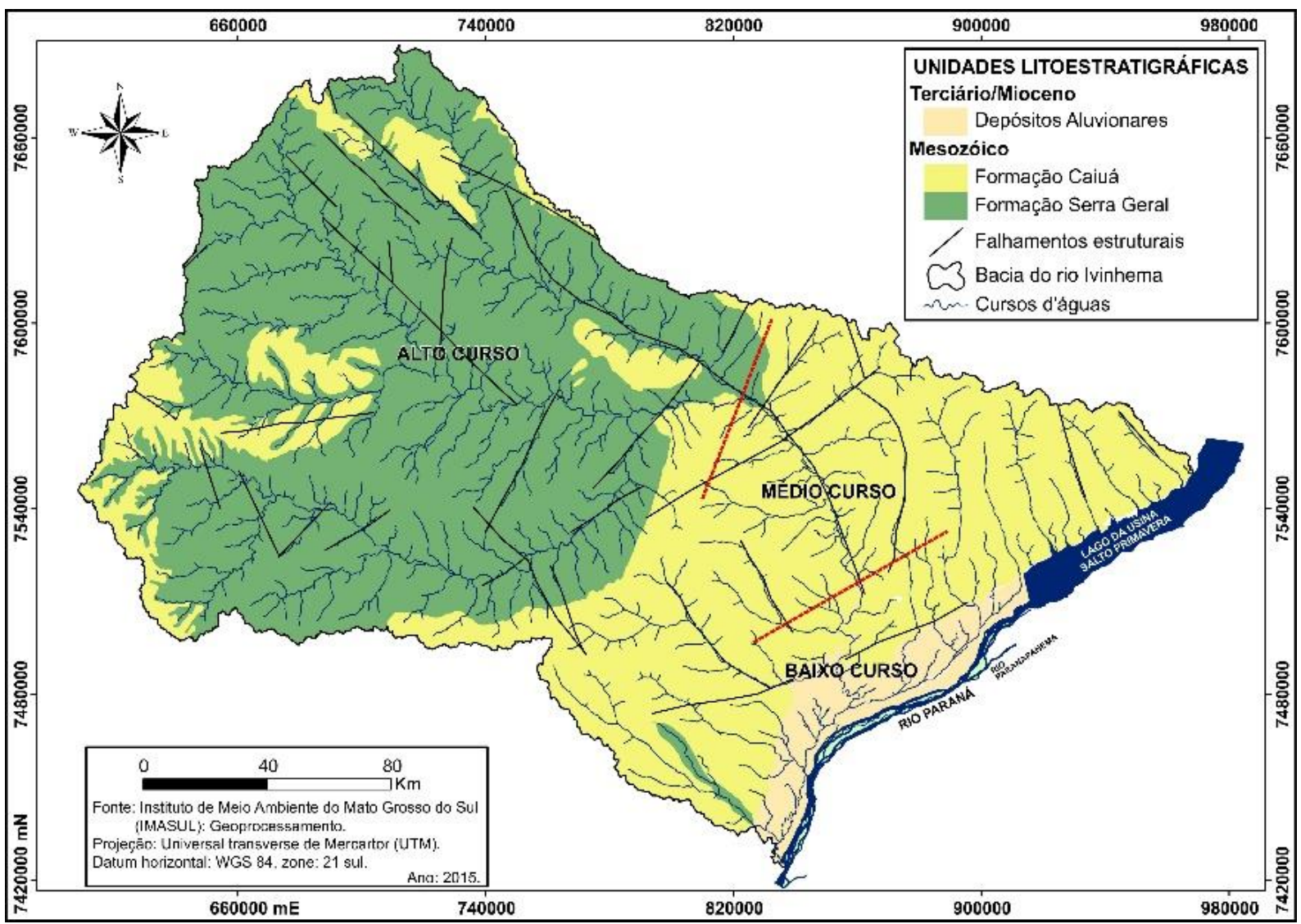

Figura 2 - Unidades geológicas da bacia hidrográfica do rio Ivinhema-MS. Fonte: Autor, com colaboração de Carlos Henrique Graça, 2015.

O rio Paraná é um rio multicanal, subdividido por inúmeras ilhas de diferentes dimensões, gerando grande número de canais, aqui denominados de secundários. Cada canal secundário apresenta características próprias de hidrodinâmica, de transporte de sedimentos, de velocidade de fluxos e de processos geomorfológicos, por isso cada confluência tem suas próprias características. A rigor as confluências estudadas se dão em frente a ilhas do rio Paraná, portanto os dados de carga e vazão apresentados se referem a estes canais e não a vazão de toda a seção do rio Paraná na área de confluência. 


\section{AS CARACTERÍSTICAS NA MORFOLOGIA E DA CARGA DE FUNDO NAS CONFLUÊNCIAS DO RIO IVINHEMA-MS COM O RIO PARANÁ}

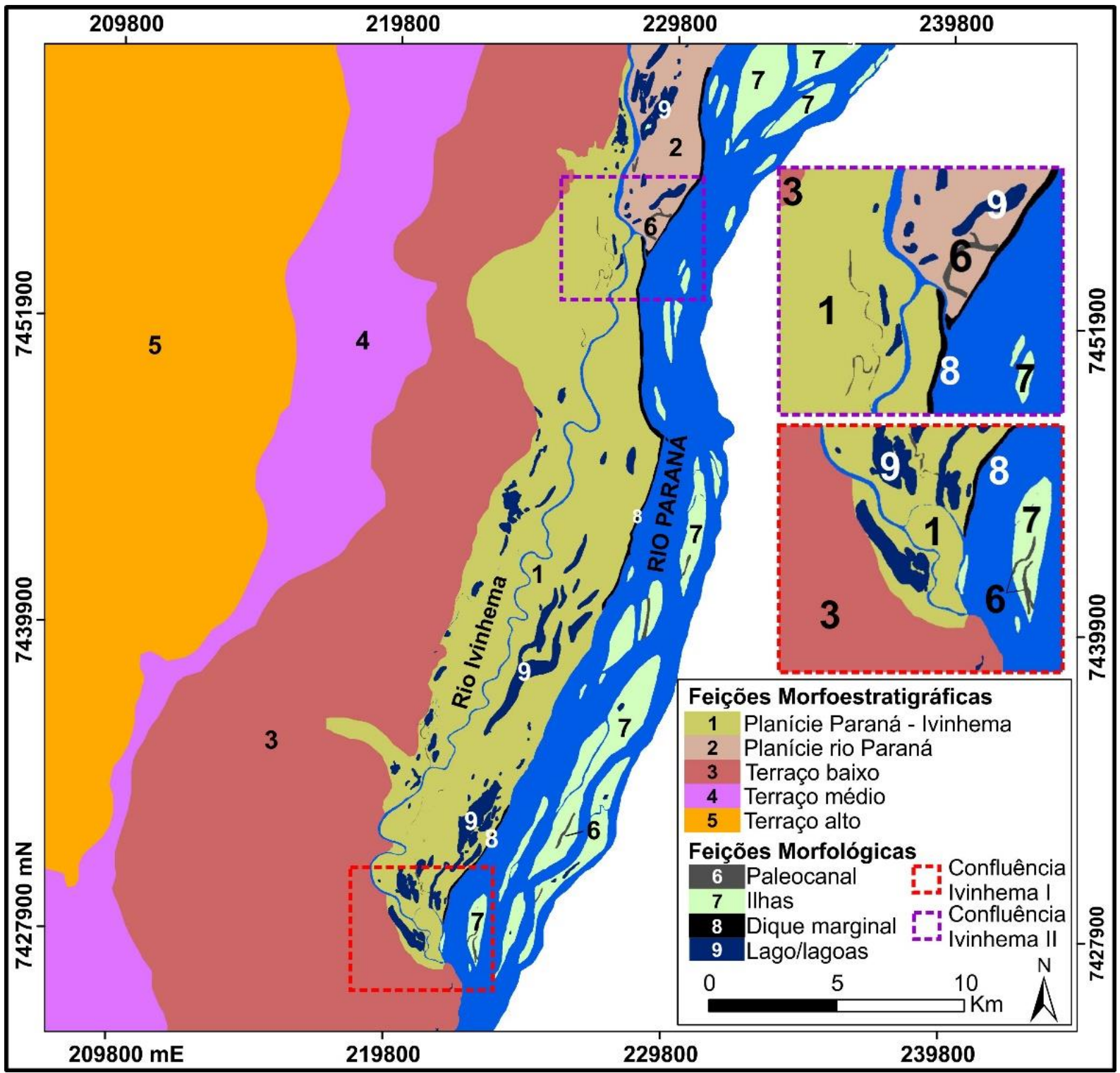

Figura 3-Geomorfologia das confluências do rio Ivinhema-MS. Fonte: Autor, com colaboração de Carlos Henrique Graça, 2015 - adaptado de Fortes (2003, p.56).

Na região Norte da área de estudo, na área na confluência Ivinhema 03, próxima à cidade de Diamante do Norte, no Paraná, tem início a área denominada de planície ParanáIvinhema, cortada pelo rio Ivinhema-MS até a confluência Ivinhema 01.

Nesta confluência, o rio Ivinhema-MS divide-se em dois canais, um dos canais segue a direção leste até desaguar nas águas do rio Paraná. O outro corta a planície ParanáIvinhema, no sentido sul/sudeste, com muitos meandros e percorrendo $40 \mathrm{~km}$ até desaguar na confluência Ivinhema 01. A distância entre as confluências Ivinhema 01 e Ivinhema 3 é de $30 \mathrm{~km}$ em linha reta; a diferença de $10 \mathrm{~km}$ de percurso demonstra a importância do rio Ivinhema-MS como agente modificador da planície Paraná-Ivinhema.

O rio Ivinhema-MS após percorrer a planície Paraná-Ivinhema, a aproximadamente 2,7 km, da sua foz, divide-se em dois canais um deles origina o canal principal denominada confluência Ivinhema 01 (ao sul), o segundo, a confluência Ivinhema 02 (ao norte), que é capturado por uma anomalia de drenagem. 


\section{AS CARACTERÍSTICAS NA MORFOLOGIA E DA CARGA DE FUNDO NAS CONFLUÊNCIAS DO RIO IVINHEMA-MS COM O RIO PARANÁ}

Ao longo da planície os inúmeros canais, paleocanais e lagoas são abastecidos pelo lençol freático aflorante e influenciado pelo nível da água do rio Paraná ou são abastecidos durante os períodos de cheia de ambos os rios. Muitas destas geoformas podem secar durante períodos de estiagem.

Esta pesquisa procura compreender os processos de construção geomorfológica das áreas de confluência, por meio da dinâmica sedimentar, geometria dos canais nas áreas de confluência do rio Ivinhema-MS com o rio Paraná.

O conhecimento da dinâmica e geomorfologia das confluências é um elemento importante para estudos ambientais neste ecossistema, pois permite a análise do comportamento do período de cheias dos canais fluviais e sua inter-relação com a planície e a carga transportada.

\section{MATERIAIS E MÉTODOS}

Para a realização desta pesquisa foram coletados dados de campo em 12 seções transversais no canal dos rios, dados obtidos por sensoriamento remoto, posteriormente trabalhados em ambiente digital e dados bibliográficos. Realizaram-se quatro campos de coleta, nos meses de fevereiro, maio, julho e novembro do ano de 2013, abrangendo períodos de diferentes vazões nos canais. Isso possibilitou a análise das modificações na morfologia do canal, na vazão, na carga sedimentar hidrotransportada.

As seções transversais estão numeradas de jusante para montante em ordem crescente. Nas confluências do rio Ivinhema 01 e Ivinhema 02 foram escolhidas sete seções transversais: três no canal principal (rio Paraná) e as demais no rio Ivinhema-MS. $\mathrm{Na}$ confluência do Ivinhema 03, foram escolhidas cinco seções transversais: sendo duas no canal do rio Paraná e três no tributário. A Figura 4 mostra as localizações dos transectos na região das confluências Ivinhema 01, 02 e Ivinhema 03. As coletas de dados e materiais nas seções ocorreram próximas às margens direita e esquerda e no meio do canal.

Para o reconhecimento da área de estudo utilizou-se de produtos de sensoriamento remoto, cartas topográficas e fotos aéreas. Iniciou-se com a análise das morfologias presentes nas áreas das confluências abordadas na pesquisa. Estas áreas foram previamente identificadas por intermédio de dados orbitais a partir da construção de um banco de dados georreferenciados com projeção UTM (Unidade Transverse de Mercartor), fuso 21 sul e datum horizontal WGS 84 organizados no Software de geoprocessamento ArcGis (ArcMap) versão 10.1 (free trial). Foram utilizados para definição das formas do relevo imagens SRTM (Shuttle Radar Topography Mission) do projeto TOPODATA (INPE, 2011) e as imagens orbitais do satélite Landsat 7, sensor ETM + (órbita 224 e ponto 77), com passagem no dia 16 de fevereiro de 2014. Estas tiveram a finalidade de discriminação das geoformas, como a dos paleocanais e paleoilhas e do mapeamento geomorfológico das áreas das confluências e geração de outros produtos cartográficos. Foi realizado também um levantamento de campo nas áreas para verificar in loco a presença de algumas dessas geoformas.

Para a elaboração de modelos e mapas batimétricos para análise da morfologia dos canais nas confluências estudadas, foi utilizada uma ecossonda da marca Furuno GP-1650-F, acoplada a um GPS Sistema de Posicionamento Global de 12 canais. Um computador portátil fez a captura, processamento dos sinais georreferenciados por meio de Software FUGAWI 4.5 e exporta na forma de arquivo de texto, para posteriormente interpolação (CARVALHO et al., 2000, p. 82; CARVALHO, 2008,p. 82 e; FRANCO, 2007, p. 38).

Os mapas batimétricos das confluências dos rios Ivinhema/Paraná foram elaborados utilizando o Software Surfer, versão 9, aplicando o método reticulado kringing para realizar a interpolação de dados, com os quais foram gerados os valores para a construção das 


\section{AS CARACTERÍSTICAS NA MORFOLOGIA E DA CARGA DE FUNDO NAS CONFLUÊNCIAS DO RIO IVINHEMA-MS COM O RIO PARANÁ}

isolinhas. Posteriormente, foram organizados e

Corel Draw X4.

editados utilizando o software de edição gráfica

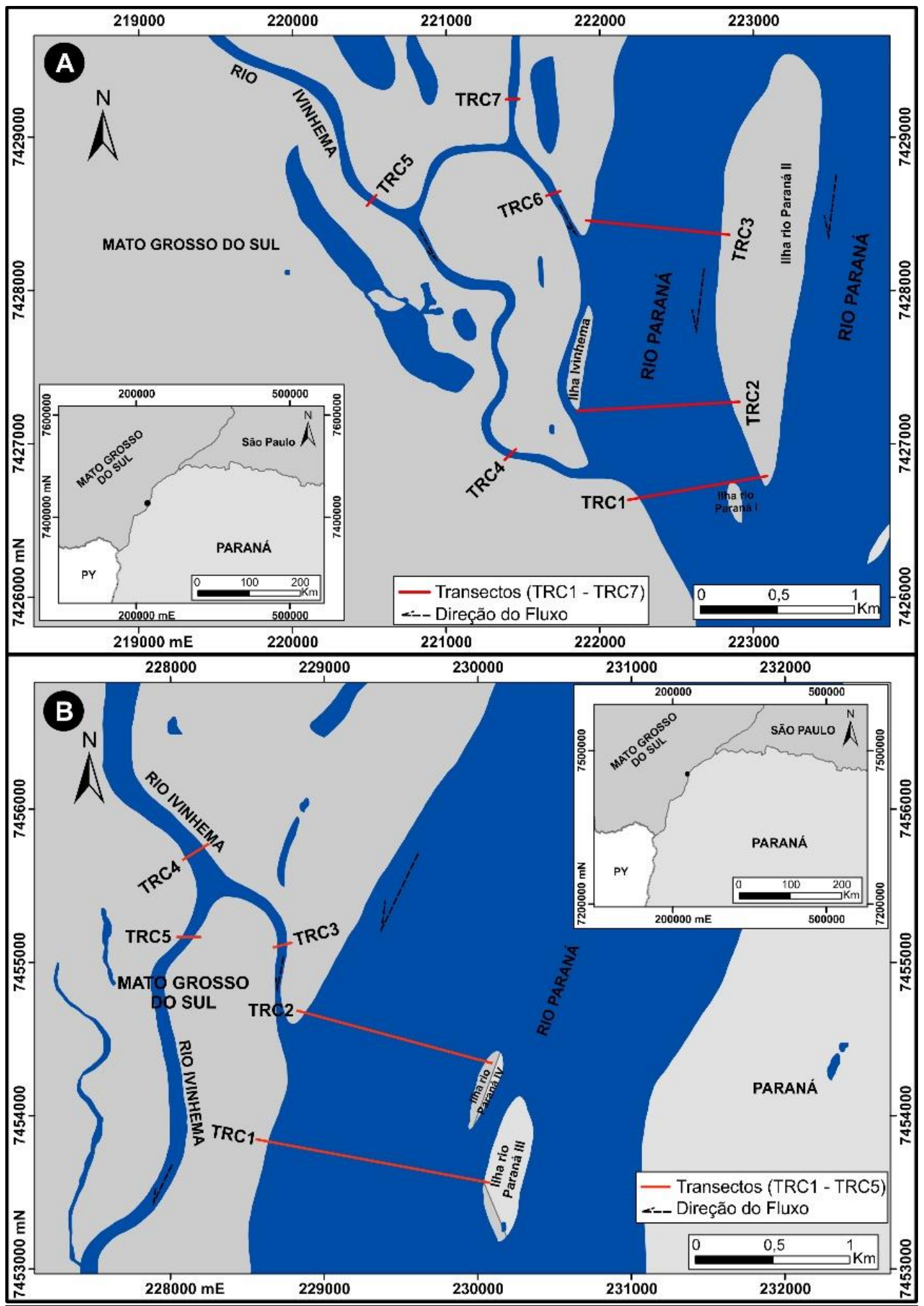

Figura 4 - Localização das seções transversais nas confluências, Ivinhema 01, 02 e 03. Fonte: Autor, com colaboração de Carlos Henrique Graça, 2015. 


\section{AS CARACTERÍSTICAS NA MORFOLOGIA E DA CARGA DE FUNDO NAS CONFLUÊNCIAS DO RIO IVINHEMA-MS COM O RIO PARANÁ}

Os dados sobre velocidade de fluxo, vazão do canal e direção de fluxos no momento da coleta foram obtidos com o uso de um Acustic doppler current profiler (ADCP) instalado no barco, que percorria em velocidade constante cada seção transversal.

Para a coleta de carga de fundo e de carga supensa, em três pontos ao longo das seções transversais (margem direita, margem esquerda e canal), foram utilizados amostradores de mandíbula e garrafa de Van Door. As amostras foram secas em temperatura ambiente.

Entre os diversos métodos utilizados para selecionar o tamanho das partículas, esta pesquisa utilizou-se do peneiramento para as amostras de areia, e as amostras com textura pelítica foram lavadas em solução de hidróxido de sódio a 40\% (SUGUIO, 1973 P. 49-58).

\section{RESULTADOS E DISCUSSÃO}

3.1. Análise geomorfológica e granulométrica das confluências Ivinhema 01 e 02

A ecobatimetria da região das confluências Ivinhema 01 (ao sul) e Ivinhema 02 (ao norte), apresentada na Figura 5 (A, B, C e D) referentes às campanhas dos meses de fevereiro, maio, julho e novembro de 2013, revela aspectos e evolução geomorfológica da área das confluências.
A cofluência Ivinhema 01 (sul) possui um ângulo de 68,5 o em formato semelhante de um " $Y$ " inclinado, (Figura 6). Na margem direita encontramos cascalheiras da geração Calcedônica (SANTOS, 1997, p.41 e FORTES, 2003, p.95) que impõem resistência aos processos erosivos direcionando o fluxo do rio Ivinhema-MS e do Paraná para o centro do canal no sentido norte/nordeste.

A área de escavamento (BEST, 1988, p.487; e BEST; ASHOWRTH, 1997 p. 276-277) surge do encontro dos fluxos de ambos os rios seguindo o mesmo sentido com profundidades de até $9 \mathrm{~m}$ e por aproximadamente 150/200 m.

A confluência Ivinhema 02 (Figura 6) origina-se da captura de drenagem do tributário pelo rio Paraná, possui ângulo de 40 은 na forma de "' $Y$ " fechado. Disso decorre aumento nos processos erosivos (aceleramento de fluxos e vórtices) na área de escavamento, que surge após o encontro do rio Ivinhema-MS na sua margem esquerda $(0,8$ a $09 \mathrm{~m} / \mathrm{s})$ com a margem direita do rio Paraná $(09$, a $1,3 \mathrm{~m} / \mathrm{s})$. $\mathrm{Na}$ margem direita do rio Ivinhema-MS as velocidades de fluxo são menores $(0,3 \mathrm{~m} / \mathrm{s})$, portanto as velocidades de fluxo nesta seção são duas a três vezes maiores na margem direita esquerda. 


\section{AS CARACTERÍSTICAS NA MORFOLOGIA E DA CARGA DE FUNDO NAS CONFLUÊNCIAS DO RIO IVINHEMA-MS COM O RIO PARANÁ}

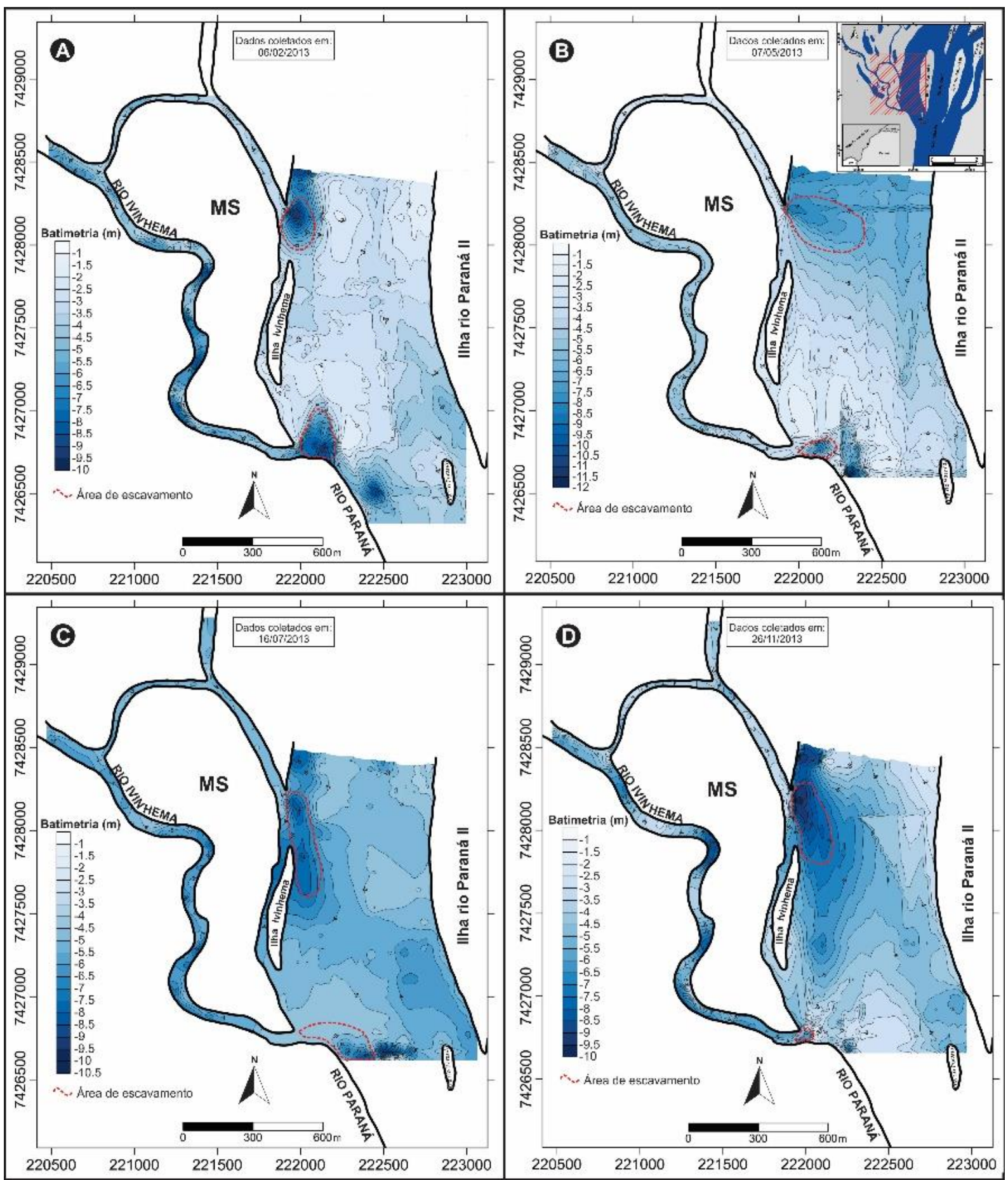

Figura 5 - Mapas batimétricos dos quatro campos da confluência do Ivinhema 01 e Ivinhema 02, 2013.

Fonte: Autor, com colaboração de Carlos Henrique Graça, 2015.

Após a confluência, já no rio Paraná, o talvegue segue a direção sul/sudeste, pois o fluxo é desviado pela presença de uma pequena ilha aluvial localizada logo a jusante da confluência. Este depósito forma uma zona de sombra ao fluxo, diminuindo sua velocidade e favorecendo a geração de uma área de estagnação entre as confluências Ivinhema 01 e 02. A presença desta ilha por si só já demonstra que esta área é um sítio deposicional, além da menor velocidade de entrada das águas do rio Ivinhema pela margem direita $(0,3$ a $0,4 \mathrm{~m} / \mathrm{s})$. 


\section{AS CARACTERÍSTICAS NA MORFOLOGIA E DA CARGA DE FUNDO NAS CONFLUÊNCIAS DO RIO IVINHEMA-MS COM O RIO PARANÁ}

Por outro lado, está ilhota também desloca o talvegue o rio Paraná, mais para o centro do canal, promovendo ai uma área de alta energia com velocidades de fluxos de 1,1 a 1,3 m/s.

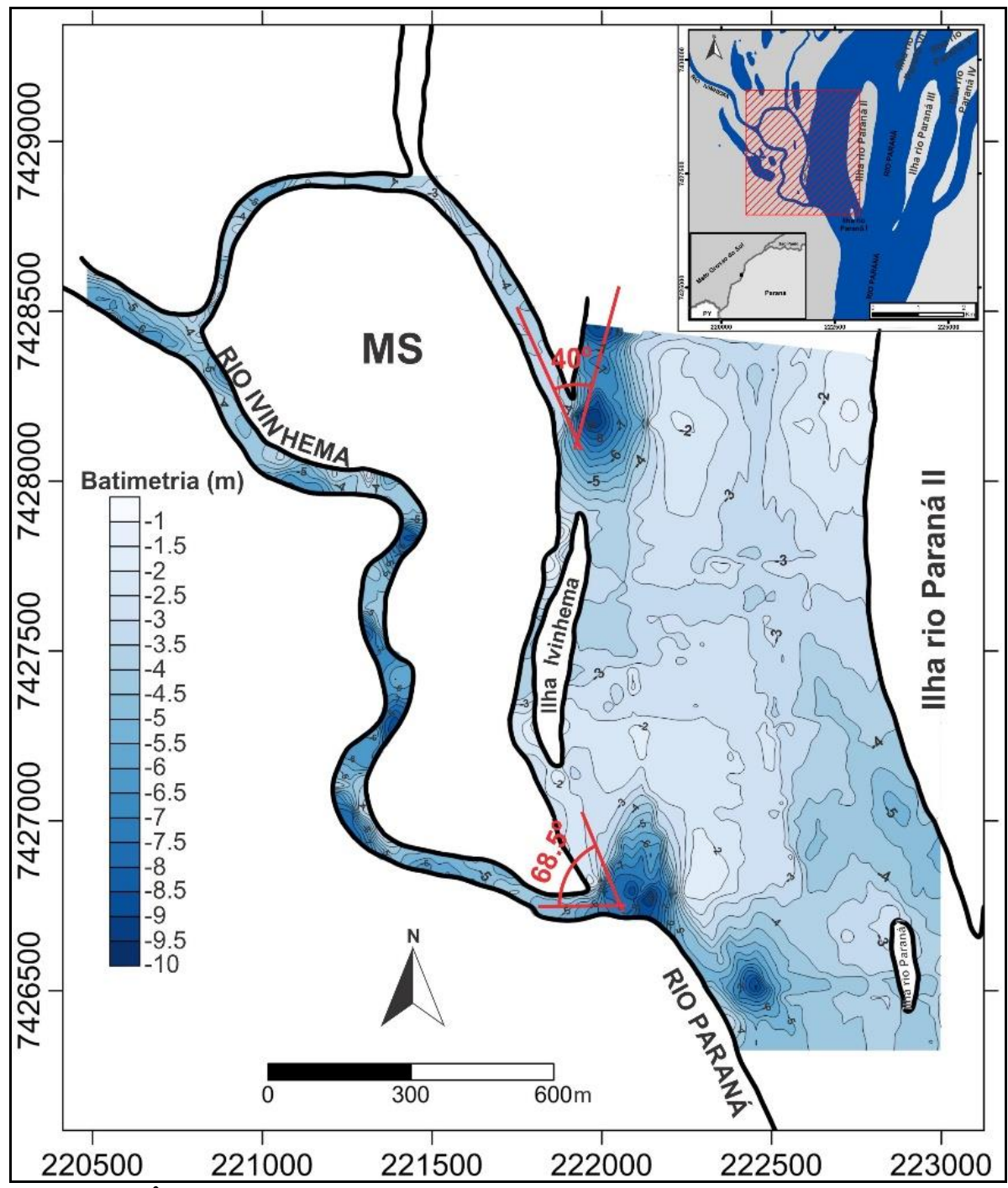

Figura 6 - Ângulo das confluências do Ivinhema 01 e Ivinhema 02 com o rio Paraná. Fonte: Autor, com colaboração de Carlos Henrique Graça, 2015.

O rio Paraná movimenta grandes quantidades de carga de fundo durante todo o ano, como observado pelas alterações na morfologia do canal mostrada nos mapas batimétricos. Em épocas de cheia como em junho-julho/2013, estes valores elevam-se de forma significativa, pois a área de escavação da confluência Ivinhema 01 foi colmatada por depósitos de areia, transportadas pelo rio (Figura 6. C). Na campanha subsequente, no mês de novembro, estabelece-se neste local novamente a área de escavamento, mostrando que o sítio é sujeito a sensíveis e persistentes processos erosivos. Martins e Stevaux (2005, p.49) estimou que o transporte médio da carga de fundo no rio Paraná na região de Porto São José em 2.820,6 ton./dia ou 1.029.300 ton./ano.

Na confluência Ivinhema 02 , no mês de junho-julho/2013, também houve grande movimentação de carga de fundo, mas a área de escavamento se manteve, embora com profundidades menores, devido ao acúmulo de sedimentos nos momentos de menores 


\section{AS CARACTERÍSTICAS NA MORFOLOGIA E DA CARGA DE FUNDO NAS CONFLUÊNCIAS DO RIO IVINHEMA-MS COM O RIO PARANÁ}

velocidades de fluxo. A manutenção da área de escavamento é explicada pela velocidade elevada do encontro dos fluxos dos rios Ivinhema-MS e o do Paraná, com médias elevadas entre $1,0 \mathrm{~m} / \mathrm{s}$ a $1,6 \mathrm{~m} / \mathrm{s}$, gerando atrito entre os fluxos, e aumentando a energia de vórtices e a sua capacidade de erodir o leito do canal. Outro fator que influencia na manutenção desta área de erosão é a proximidade do talvegue do rio Paraná nesta margem. Estes processos na área de escavamento também foram notados por Best (1986, p.161 ; 1988 p. 487); Best e Ashwort, (1997, p.276) nas confluências fluviais por eles analisadas.

As características geomorfológicas do leito e da confluência interferem na distribuição e transporte da deposição carga de fundo. Entre as confluências 01 e 02 o talvegue do rio Paraná desenvolve uma área de escavamento devido as maiores velocidades de fluxo nesta área. Este fato aumenta a energia do fluxo e a capacidade de transporte do material mais grosseiro, justificando a presença de areia grossa e cascalho no centro do canal e eventualmente próximo à margem direita das seções 1 e 2, respectivamente (Figura 7).

A presença contínua de material pelítico (lama) na margem direita da seção 2 está relacionada à área de estagnação localizada entre as confluências o que favorece a deposição de material em suspensão. 0 principal material encontrado entre as seções analisadas foi areia fina e média, sendo esta a fração granulométrica mais coletada no leito do canal. (Figura 7).

A seção transversal 4 , a montante da confluência Ivinhema 01 , no rio tributário predomina a areia. Esta fração decorre da dinâmica do rio Paraná, que invade com frequência o rio Ivinhema-MS por meio da margem esquerda deste canal, depositando sua carga nos períodos de cheia do canal principal.

A seção transversal 6, a montante da confluência Ivinhema 02, próximo à margem tem-se a ocorrência de areia e de material pelítico. Na margem direita com baixa energia de fluxo, o teor de silte e argila aumenta e é neste local que se inicia a área de estagnação de fluxo proposto por Best (1987, p. 28).

\section{Valores percentuais médios da carga de fundo confluências Ivinhema 01 e Ivinhema $02-2013$}

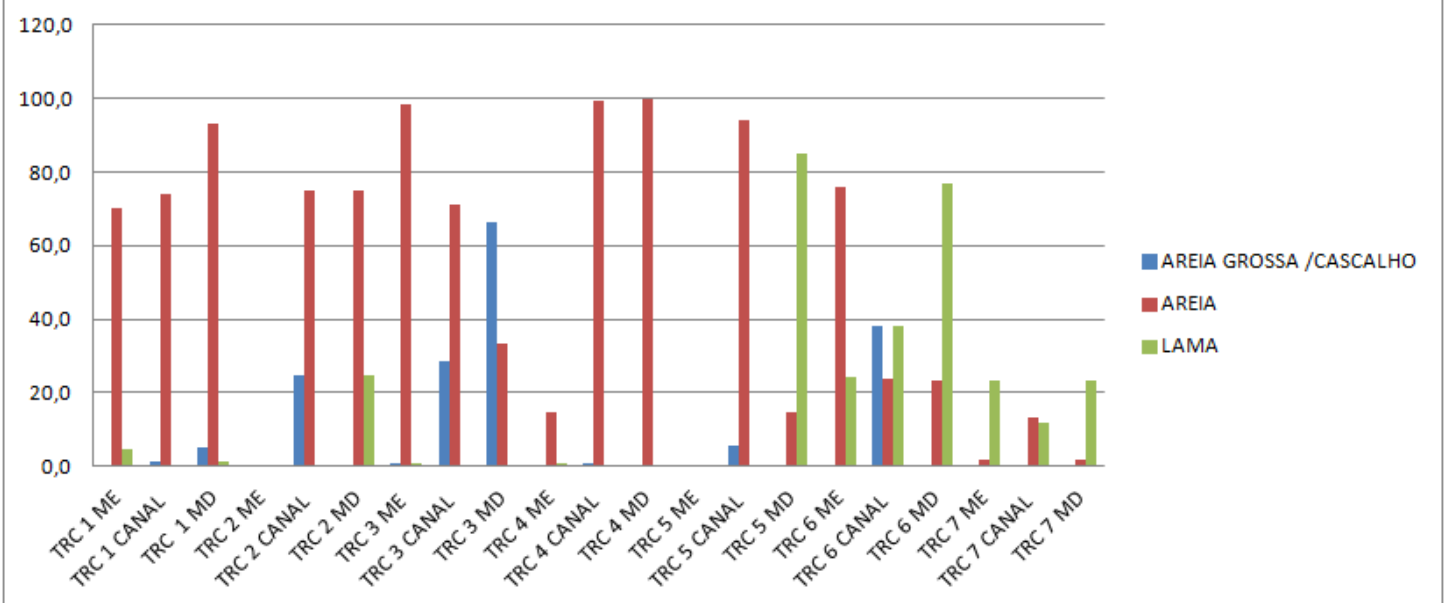

Figura 7 - Valores percentuais médios de carga de fundo nas seções transversais confluências Ivinhema

01 e 02. Fonte: Autor, 2015. Na legenda TRC1 ME, TRS1 canal e TRC1 ME significam: (TRC) seção transversal 1, (ME) margem esquerda, (MD) margem direita e (canal) significa o centro da seção e assim sucessivamente. 


\section{AS CARACTERÍSTICAS NA MORFOLOGIA E DA CARGA DE FUNDO NAS CONFLUÊNCIAS DO RIO IVINHEMA-MS COM O RIO PARANÁ}

A seção transversal 5, localizada no rio Ivinhema-MS, possui fundo rochoso irregular, pequenas depressões do leito que favorecem a deposição de sedimentos quando a velocidade da corrente próxima ao leito diminui, aumentando a deposição temporária de areia no canal e na margem direita além da deposição de material de granulometria pelítica, como ocorreu após a cheia de junho e julho de 2013. Esta situação deve-se ao barramento do rio Ivinhema-MS pelo aumento do nível do rio Paraná e alagamento da planície. A margem esquerda demonstrou-se mais dinâmica alternando as frações granulométricas.

A seção transversal 7, rio IvinheimaMS, teve sua primeira coleta em julho de 2013, após um período de cheia. No momento da coleta apresentou uma vazão inferior a $6 \mathrm{m3} / \mathrm{s}$ e grandes quantidades de vegetação nas margens que favorecem a deposição de material siltico argiloso e areia muito fina.

\subsection{Análise geomorfológica e granulométrica da confluência Ivinhema 03}

Os mapas batimétricos da confluência Ivinhema 03 revelam que a morfologia do leito da confluência teve pequenas alterações entre as campanhas. A montante da confluência próximo à margem direita, seguindo a direção sul-sudeste, ocorre a área mais rasa do canal secundário do rio Paraná (Figura 8). Próximo à margem esquerda a morfologia se manteve mais uniforme entre as seções 01 e 02 . O talvegue localiza-se nesta área com profundidades médias de 6 a $7 \mathrm{~m}$ e máximas de até $8 \mathrm{~m}$ abaixo do nível do rio. $\mathrm{A}$ área central do canal possui as menores profundidades pela grande movimentação de carga de fundo.

A confluência Ivinhema 03 possui ângulo de $44,8^{\circ}$ (Figura 9) e tem a forma de um " $Y$ " inclinado; o talvegue do rio Ivinhema-MS localiza-se na margem direita nesta área, favorecendo o avanço das águas em direção ao rio Paraná. O tributário apresenta uma vazão próxima a $1 \%$ da vazão do canal secundário do rio Paraná, portanto não tem energia de fluxo quando avança sobre o canal principal limitando sua penetração a poucas dezenas de metros da margem direita até a mistura total dos fluxos que só vai ocorrer a alguns quilômetros abaixo.

A área de escavamento da confluência segue pela margem direita do rio Paraná e aumenta quando avança em direção sul/sudeste. Antes do encontro dos canais, no rio ivinheima-MS, as profundidades médias são de 4 a $5 \mathrm{~m}$ e, após o encontro das águas dos dois rios, aumentam para 6 a $8 \mathrm{~m}$. A largura da área de escavamento aumenta até próximo ao centro do canal do rio Paraná.

Na seção transversal 5, a montante da divisão dos canais do rio Ivinhema-MS, com profundidades entre 4 a $6 \mathrm{~m}$ em média, sendo maiores na margem direita. Observa-se que após a divisão, o canal principal segue cortando a planície Paraná/Ivinhema até as confluências Ivinhema 01 e 02, e possui profundidades iniciais de 5 a $6 \mathrm{~m}$. O outro canal já citado anteriormente segue em direção ao rio Paraná. 


\section{AS CARACTERÍSTICAS NA MORFOLOGIA E DA CARGA DE FUNDO NAS CONFLUÊNCIAS DO RIO} IVINHEMA-MS COM O RIO PARANÁ

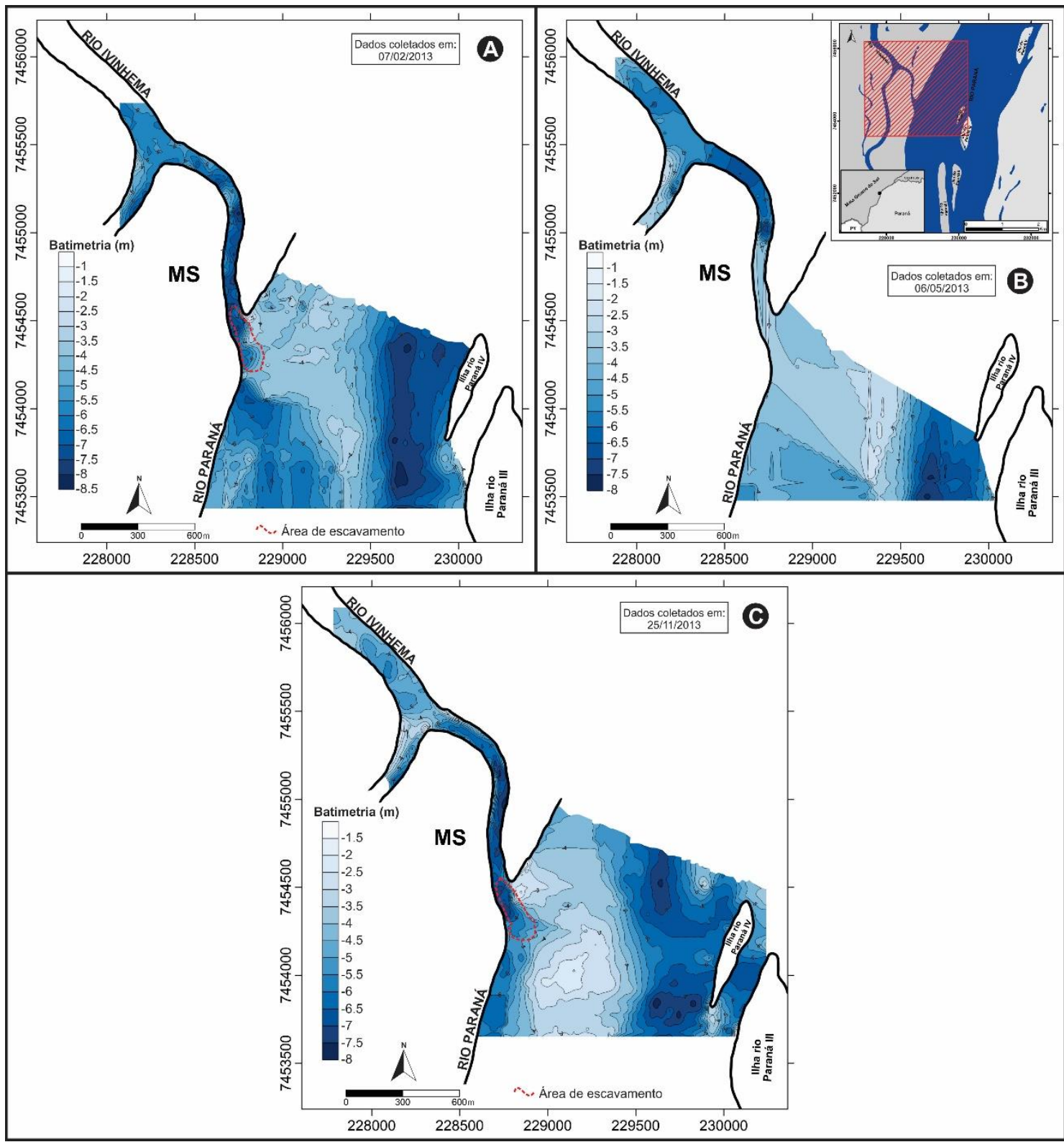

Figura 8 - Mapas batimétricos dos campos da confluência do Ivinhema 03 - 2013. Fonte: Autor, com colaboração de Carlos Henrique Graça, 2015. 


\section{AS CARACTERÍSTICAS NA MORFOLOGIA E DA CARGA DE FUNDO NAS CONFLUÊNCIAS DO RIO IVINHEMA-MS COM O RIO PARANÁ}

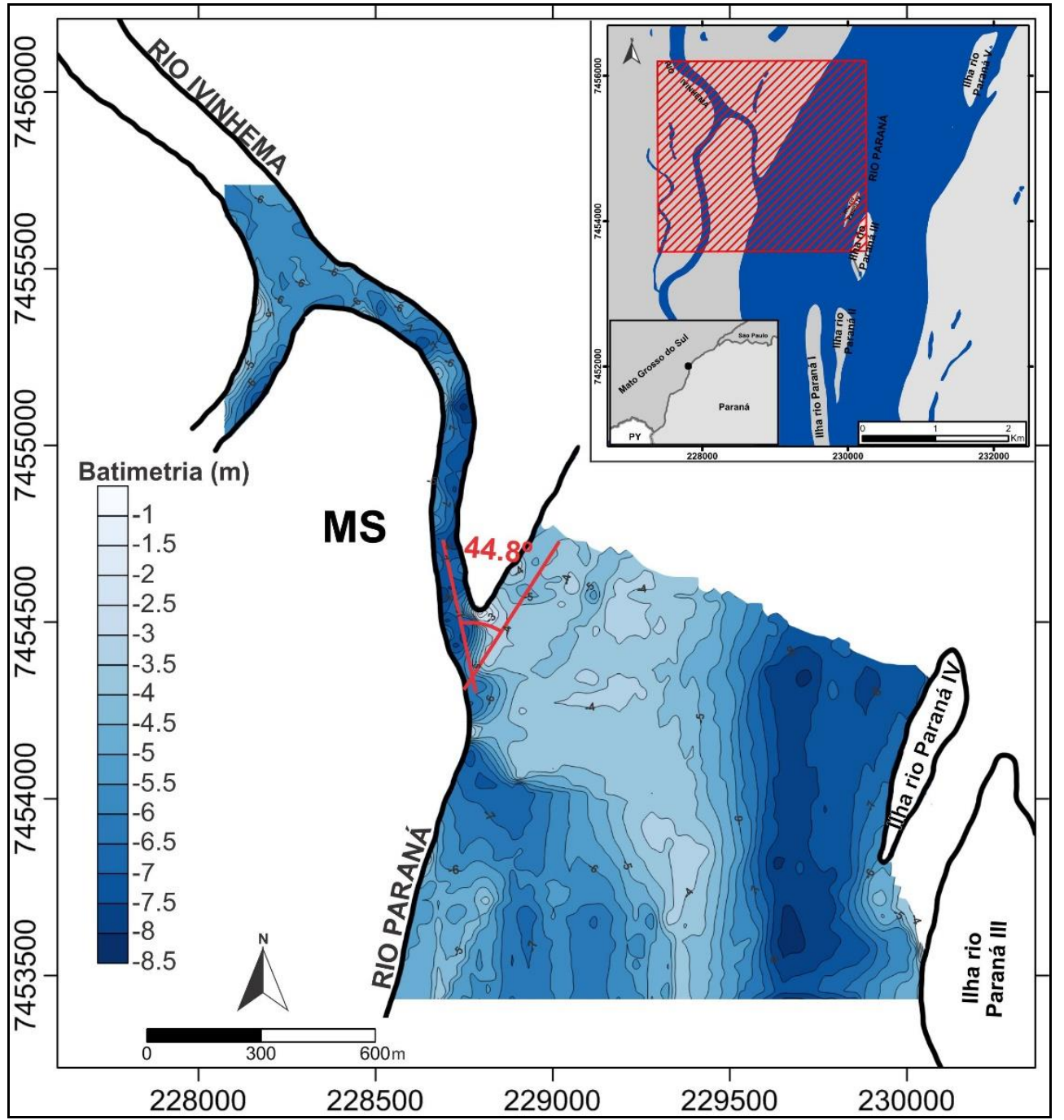

Figura 9. Ângulo da confluência Ivinhema 03 com o rio Paraná. Fonte: Autor, com colaboração de Carlos Henrique Graça, 2015.

Analisando a Figura 10, verifica-se que a areia é a principal fração granulométrica presente em quase todas as seções transversais da confluência Ivinhema 03.

A presença de lama e argila foi significativa nas margens direitas das seções transversais 1 e 2 e 5 . As duas primeiras localizadas no rio Paraná margeiam a planície Paraná/Ivinhema. Nesta área predomina a presença de depósito de lâminas de argila nas margens e fundo do canal.

$\mathrm{Na}$ seção transversal 4, no rio Ivinhema-MS, o fluxo principal segue a planície Paraná/Ivinhema. O canal possui profundidades uniformes entre as margens, porém no centro torna-se ligeiramente mais profundo e com velocidades maiores de fluxo (08 a $1 \mathrm{~m} / \mathrm{s}$ ); constatamos a presença de fundo rochoso. $\mathrm{Na}$ margem direita com velocidades de fluxo de $(0,6$ a $0,7 \mathrm{~m} / \mathrm{s})$ ocorre a deposição de areia e areia grossa e cascalho, principalmente em eventos de cheias quando as velocidades são superiores, enquanto na margem esquerda com velocidades inferiores $(0,4 \mathrm{~m} / \mathrm{s})$ ocorre a deposição de lama. 


\section{AS CARACTERÍSTICAS NA MORFOLOGIA E DA CARGA DE FUNDO NAS CONFLUÊNCIAS DO RIO IVINHEMA-MS COM O RIO PARANÁ}

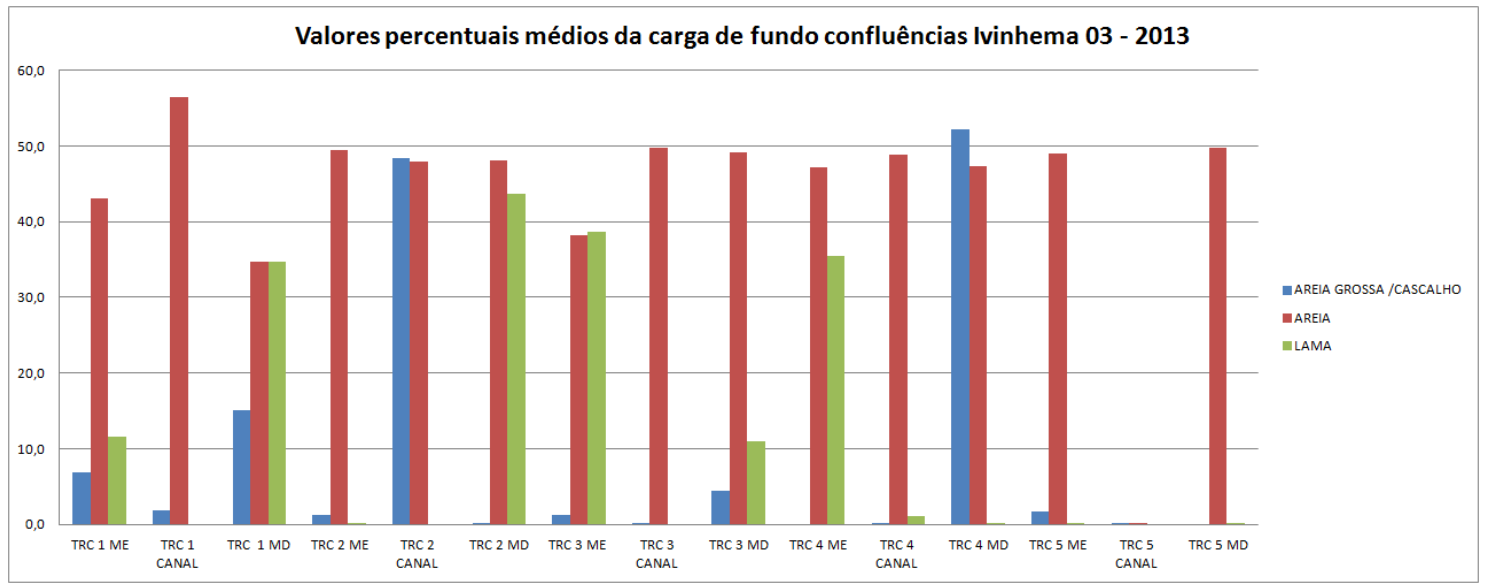

Figura 10 - Dados granulométricos da confluência do rio Ivinhema-MS. Fonte: Autor, 2015.

A seção transversal 3 localiza-se no rio Ivinhema-MS. Próximo à margem esquerda ocorrem as maiores profundidades no canal secundário e as menores velocidades de fluxos $(0,2$ a $0,4 \mathrm{~m} / \mathrm{s})$, devido ao represamento do canal pelo rio Paraná, que adentra por esta margem e mantém o escoamento lento; as maiores velocidades ocorrem na margem direita $(0,5$ a $0,7 \mathrm{~m} / \mathrm{s})$ que dirige o fluxo em direção ao rio Paraná. Ocorre deposição de material pelítico próximo à margem esquerda relacionado ao barramento e à erosão da margem, mas a principal fração granulométrica é a areia fina. Nesta seção verifica-se a presença de areia grossa e cascalho na margem direita e canal relacionado aos eventos de cheia de ambos os rios.

Na seção transversal 5, as maiores velocidades ocorrem no canal e próximo à margem esquerda. Este fluxo se divide em dois e pode-se observar que próximo à margem direita as velocidades são baixas $(0,3$ a 0,4 m/s) apresentando características de uma área de deflação, observa-se a presença de leito rochoso, até o início do canal que corta a planície Paraná/Ivinhema, a presença de vegetação subaquática nesta margem explica as baixas velocidades. As maiores profundidades e velocidades ocorrem na margem esquerda e no centro do canal $(0,8$ a $09 \mathrm{~m} / \mathrm{s}$ ), nela verificou-se a presença de areia no e de fundo rochoso.

\section{CONSIDERAÇÕES FINAIS}

O ângulo de confluência, a carga sedimentar e as vazões dos canais determinam a localização das zonas de escavamento (erosivas) e das zonas de estagnação (deposicionais ou de acumulação), como verificadas em toda as confluências analisadas, mesmo na confluência Ivinhema 03 que apresentou uma vazão muito pequena em relação à vazão do rio Paraná. Sugerindo que a vazão e velocidades do canal secundário (Ivinhema-MS) não são os fatores que determinam os vórtices de limpeza que promovem o escavamento, no canal principal (rio Paraná) após a confluência.

O rio Paraná promove grande movimentação de carga de fundo durante o ano, sendo mais intenso nos períodos de cheia onde ocorre grandes alterações na morfologia do leito, do fluxo e no tipo de carga transportada, nas confluências estudadas. 0 transporte de areia grossa e cascalhos ocorre nas áreas mais velozes e deposição de lama nas áreas represadas pelos rios, demostrando assim que não somente nas planícies se depositam os pelitos, mas também nos canais fluviais, mesmo em rios de grande porte.

A areia grossa e cascalho depositada no rio Ivihnema-MS está associada à erosão das cascalheiras que ocorrem na base do sistema aluvial do rio Paraná. A carga de fundo do rio Ivinhema-MS é predominantemente de areia 


\section{AS CARACTERÍSTICAS NA MORFOLOGIA E DA CARGA DE FUNDO NAS CONFLUÊNCIAS DO RIO IVINHEMA-MS COM O RIO PARANÁ}

proveniente da Formação Caiuá e da Formação Botucatu, ocorrentes na maior parte desta bacia hidrográfica.

\section{REFERÊNCIAS}

$B E S T$, J. L. The morphology of river channel confluences. Progress in Physical Geography, [S.I.], v. 10, n. 2, p. 157-174, 1986.

BEST, J. L. Flow dynamics at river channel confluences: implications for sediment transport and bed morphology. Recent Developments in Fluvial Sedimentology, [S.I.], v. 39, n. 1, p. 27-35, 1987.

BEST, J. L. Sediment transport and bed morphology at river channel confluences. Sedimentology, [S.I.], v. 35, n. 3, p. 481-498, 1988.

BEST, J. L.; ASHWORTH, P.J. Scour in large braided rivers and the recognition of sequence stratigraphic boundaries. Nature, [S.I.], v. 387, p. 275-277, 1997.

BEST, J. L.; ROY, A. G. Mixing-layer distortion at the confluence of channels of different depth. Nature, [S.I.], v. 350, p. 411-413, 1991.

CARVALHO, N. de O. et al. Guia de práticas sedimentométricas. Brasília, DF: ANEEL, 2000. $154 \mathrm{p}$.

CARVALHO, T. R. Técnicas de medição de vazão por meios convencionais e não convencionais. Revista Brasileira de Geografia Física, Recife, v. 1, n. 1, p. 73-85, 2008.

FORTES, E. Geomorfologia do baixo curso do rio Ivinhema, MS: uma abordagem morfogenética e morfoestrutural. 2003. $199 \mathrm{f}$. Tese (Doutorado em Geociências) Universidade Estadual Paulista, Rio Claro, 2003.

FORTES, E.; VOLKMER, S.; STEVAUX, J. C. Controles hidrológicos dos processos erosivos do baixo curso do rio Ivinhema, Ms. V SIMPÓSIO NACIONAL DE GEOMORFOLOGIA - I ENCONTRO SUL-AMERICANO DE GEOMORFOLOGIA, UFSM - Santa Maria, 2004 p. 1-12.
FORTES, E.; STEVAUX, J. C.; VOLKMER, S. Neotectonics and channel evolution of the Lower Ivinhema River: a right-bank tributary of the upper Paraná River, Brazil.

Geomorphology, Amstrerdam, v. 70, p. 325$338,2005$.

FORTES, E.; VOLKMER, S. Cascalheiras do baixo curso do rio Ivinhema, MS-Brasil. In: CONGRESSO DA ASSOCIAÇÃO BRASILEIRA DE ESTUDOS DO QUATERNÁRIO, 9., 2003, Recife. Anais... São Paulo: ABEQUA, 2003. p. 40.

FRANCO, A. A. Análise da dinâmica de fluxo e morfologia na confluência dos rios Ivaí e Paraná, PR/MS. 2007. 82 f. Dissertação (Mestrado)-Universidade Guarulhos, Guarulhos, 2007.

INPE (Instituto de Pesquisas Espaciais). Projeto TOPODATA. 2011. Disponível

em: http://www.dsr.inpe.br/topodata/>. Acess o em 15 de julho de 2014.

MARTINS. Débora Pinto. Formas de leito e transporte de carga de fundo do Alto rio Paraná. Revista Brasileira de Geomorfologia, Porto Alegre, v. 6, n. 2, p. 43-505, 2005. MATO GROSSO DO SUL. Diagnóstico da Bácia hidrográfica dop rio Ivinhema: subsídio a elaboração do plano de recursos hídricos da bacia hidrográfica do rio Ivinhema. Mato Grossso do Sul: IMASUL; SEMAC, 2014.

SANTOS, M. L. dos. Estratigrafia e evolução do sistema siliciclástico do rio Paraná no seu curso superior: ênfase a arquitetura dos depósitos, variação longitudinal das fácies processos sedimentares. 1997. 246 f. Tese (Doutorado em Geociências)- Universidade Federal do Rio Grande do Sul, Porto Alegre, 1997.

SANTOS, M. L. dos. Unidades Geomorfológicas e depósitos sedimentares associados no sistema fluvial do rio Paraná no seu curso superior. Revista Brasileira de Geomorfologia, Porto Alegre, v. 6, n. 1, p. 85-95, 2005.

SOUZA FILHO, E. E. Aspectos da geologia e estratigrafia dos depósitos sedimentares do rio Paraná entre Porto Primavera (MS) e Guaira (PR). 1993. 214 f. Tese (Doutorado em 


\section{AS CARACTERÍSTICAS NA MORFOLOGIA E DA CARGA DE FUNDO NAS CONFLUÊNCIAS DO RIO IVINHEMA-MS COM O RIO PARANÁ}

Geociências)-Universidade de São Paulo, São

Paulo, 1993.

SOUZA FILHO, E. E. e STEVAUX, J.C. Geologia e Geomorfologia do complexo rio Baia-CurutubaIvinheima. In: VAZZOLER, A. E. A. M.; AGOSTINHO, A. A.; HAHN, N. S. (Orgs.). A planície de inundação do alto rio Paraná. Maringá: Eduem, 1997. p. 1-45.

STEVAUX, J. C. O Paraná: geomorfogênese, sedimentação e evolução quaternária do seu curso superior (região de Porto Rico,PR). 1993. 242 f. Tese (Doutorado em Geociências)Universidade de São Paulo, 1993.

STEVAUX, J. C.; SANTOS, M. L.; SOUZA FILHO, E. E. Alluvial System and Quaternary evolution of Paraná River in the Souther - Central Brazil. In: GLOBAL CONTINENTAL PALAEOHYDROLOGY PROJECT - GLOCOPH, 2006, Guarulhos. Anais... Guarulhos: UNG, 2006. v. 1. p. 1-32.

SUGUIO, K. Introdução à sedimentologia. São Paulo: Ed. Edgard Blocher, 1973. 